\title{
El EBEP y los problemas relativos a la decisión de su aplicación por los parlamentos autonómicos
}

\author{
Rafael Cano Silva \\ Doctor en Derecho Administrativo \\ Jefe del Departamento de Selección, Formación y Perfeccionamiento \\ del Parlamento de Andalucía \\ SUMARIO: \\ I. INTRODUGCIÓN. II. DESDE LOS INFORMES DE ESTUDIOS \\ PREPARATORIOS PARA EL PRIMER EBEP HASTA LA ACTUA- \\ LIDAD. III. EL ÁMBITO SUBJETIVO DEL EBEP. IV. LA LEGISLA- \\ CIÓN ESPECÍFICA PROPIA DE LAS CÁMARAS PARLAMENTA- \\ RIAS DE LAS CGAA: EL ART. 4 DEL EBEP. 1. Informe de la Comisión \\ para el estudio y preparación del EBEP y los textos normativos que lo aprue- \\ ban. A. Informe de la Comisión para el estudio y preparación del EBEP. \\ B. Ley 7/2007, de 12 de abril, y Real Decreto Legislativo 5/2015, de 30 de \\ octubre, que aprueban el EBEP. C. Aplicación a las asambleas parlamenta- \\ rias de las CCAA. D. Excepción de otros colectivos del art. 4 del EBEP. 2. \\ Tramitación normativa del EBEP. 3. ¿Qué ha de entenderse por legislación \\ específica? A. El rango normativo. B. Tipo normativo: Estatutos del Per- \\ sonal, leyes de función pública de las CGAA o Estatutos de autonomía. V. \\ CONSEGUENGIAS JURÍDICAS DE LA LEGISLAGIÓN ESPECÍFI- \\ CA. VI. LÍMITES JURÍDICOS DE LAS ASAMBLEAS PARLAMEN- \\ TARIAS DERIVADOS DE LA NO APLICACIÓN DEL EBEP. VII. BI- \\ BLIOGRAFÍA.
}

RESUMEN: El EBEP, aprobado tanto por Ley 7/2007, de 12 de abril, como por Real Decreto Legislativo 5/2015, de 30 de octubre, estableció que sus disposiciones sólo se aplicarán directamente cuando así lo disponga su legislación específica a determinado personal, entre el que se encuentra el de las asambleas legislativas de las comunidades autónomas. Ello plantea diversas situaciones, teóricas y prácticas, que suscitan controversias. Entre las mismas, podemos recoger, entre otras, qué debemos entender por legislación específica para la aplicación o no del EBEP, el rango normativo necesario de los parlamentos autonómicos para que se les aplique dicho Estatuto. Analizamos en este artículo las consecuencias jurídicas de la decisión adoptada por

Recibido: 08/03/2019

Aceptado: 05/06/2019 
las cámaras autonómicas respecto al art. 4 a) sobre la aplicación o no del Estatuto así como los límites jurídicos que tienen estas asambleas para aquellos supuestos en los que se decida la no aplicación del mismo.

PALABRAS CLAVE: Competencias autonómicas, Estatutos del personal, función pública, Parlamentos autonómicos.

ABSTRACT: The EBEP, approved both by Law 7/2007, of April 12, and by Royal Legislative Decree 5/2015, of October 30, established that its provisions will only be applied directly, when its specific legislation so dictates, to certain personnel, between which is the one of the legislative assemblies of the autonomous communities. This raises various situations, theoretical and practical, which arouse controversy. Among them, we can gather, among others, what we should understand by specific legislation for the application or not of the EBEP, the necessary normative range of the autonomous parliaments to apply said Statute. We also face in this article the legal consequences of the decision adopted by the regional chambers regarding art. 4 a) on the application or not of the Statute as well as the legal limits that these assemblies have for those cases in which it is decided not to apply it.

KEYWORDS: Autonomic powers, Statutes of the staff, civil service, autonomic parliaments.

\section{INTRODUCGIÓN}

El Estatuto Básico del Empleado Público (en adelante, EBEP) está sometido a constante evolución y cambio ${ }^{1}$ debido fundamentalmente a dos razones: Una prime-

\footnotetext{
1 En apenas ocho años, ha habido un texto nuevo que sustituye al primer EBEP (Ley 7/2007, de 12 de abril, Estatuto Básico del Empleado Público), como constituye el Real Decreto Legislativo 5/2015, de 30 de octubre, por el que se aprueba el texto refundido de la Ley del Estatuto Básico del Empleado Público, en virtud de la Ley 20/2014, de 29 de octubre, por la que se delega en el Gobierno la potestad de dictar diversos textos refundidos, al amparo de lo establecido en el artículo 82 y siguientes de la Constitución Española, después de innumerables modificaciones como son: Ley 40/2007, de 4 de diciembre, de Medidas de Seguridad Social, Real Decreto-ley 8/2010, de 20 de mayo, por el que se adoptan medidas extraordinarias para la reducción del déficit público, Ley 39/2010, de 22 de diciembre, de Presupuestos Generales del Estado para el año 2011, Ley 27/2011, de 1 de agosto, Reforma de las pensiones, Ley 26/2011, de 1 de agosto, de adaptación normativa a la Convención Internacional sobre los Derechos de las Personas con Discapacidad, Real Decreto Legislativo 2/2011, de 5 de septiembre, por la que se aprueba el Texto Refundido de la Ley de Puertos del Estado y de la Marina Mercante, Real Decreto-ley 20/2012, de 13 de julio, por el que se aprueban medidas para garantizar la estabilidad presupuestaria y de fomento de la competitividad, Ley Orgánica 9/2013, de 20 de diciembre, de control de la deuda comercial en el sector público, Ley 27/2013, de 27 de diciembre, de racionalización y sostenibilidad de la Administración Local, Ley 15/2014, de 16 de septiembre, de racionalización del Sector Público y otras medidas de reforma administrativa, Real Decreto-ley $1 / 2015$, de 27 de febrero, por el que se aprueba el mecanismo de segunda oportunidad, reducción de carga financiera y otras medidas de orden social, Ley 25/2015, de 28 de julio, de mecanismo de segunda
} 
ra, interna, que reclamaba una adaptación y reestructuración de la función pública, como se explicita en el subepígrafe siguiente; la segunda, por aplicación del Derecho europeo.

Dentro de esta última razón, dos hitos marcan la nueva vía, y que por supuesto, los estatutos del personal (en adelante, EEPP) no pueden resultar ajenos. Son la no discriminación por razón de la nacionalidad y la protección de los derechos sociales de los empleados públicos. Derechos, en suma, que no solo deben recoger los diferentes EEPP, sino que son totalmente exigibles ante la jurisdicción competente.

De modo análogo a lo que sucede con los EEPP respecto al resto de las normas en materia de función pública estatal, la aplicación del Derecho europeo en cuanto a la aplicación de unos derechos y principios exigibles, a través, fundamentalmente, de la evolución expansiva de la jurisprudencia del Tribunal de Justicia, manifiestos principalmente en libertades económicas y derechos sociales, hace que se consiga un efecto homogeneizador de los distintos Derechos nacionales (incluidos los autonómicos) respecto a la función pública, sin que se pueda catalogar como unificación del régimen jurídico de los empleados públicos en la Unión Europea (en adelante, UE).

Posiblemente, ello haya redundado en una mejor coordinación entre el legislador estatal básico y los legisladores autonómicos, así como una mejor interpretación de la jurisprudencia del Tribunal Constitucional y del Tribunal Supremo en las tareas encomendadas por el ordenamiento jurídico vigente.

En definitiva, la jurisprudencia europea tiene como consecuencia una homogeneización del estatuto de los empleados públicos, es decir, funcionarios, laborales, y estatutarios; todo ello, sin menoscabo de la libertad que el EBEP otorga a distintas administraciones en orden a la regulación jurídica del personal dependientes de las mismas, y por supuesto, sin menoscabo de la autonomía parlamentaria de los parlamentos autonómicos en orden a la elaboración y aprobación normativa de sus respectivos EEPP.

Esta homogeneización está en contraste con la heterogeneidad que ofrece el EBEP, propiciándosela a los regímenes jurídicos de función pública existentes en el ordenamiento jurídico español porque ofrece un sistema que se caracteriza por la flexibilidad. Ello está en perfecta sintonía con la autonomía organizativa de las asambleas parlamentarias, las cuales, podrán construir su propio régimen de función

oportunidad, reducción de la carga financiera y otras medidas de orden social, Ley 26/2015, de 28 de julio, que modifica el sistema de protección a la infancia y a la adolescencia, Ley Orgánica 9/2015, de 28 de julio, de Régimen de Personal de la Policía Nacional, Real Decreto-ley 10/2015, de 11 de septiembre, por el que se conceden créditos extraordinarios y suplementos de crédito en el presupuesto del Estado y se adoptan otras medidas en materia de empleo público y de estímulo a la economía y Ley 48/2015, de 29 de octubre, de Presupuestos Generales del Estado para el año 2016. 
pública, en aras de la independencia parlamentaria frente a poderes ajenos al órgano legislativo, especialmente el Poder Ejecutivo.

FONDEVILA ANTOLÍN señala que el EBEP ofrece a las comunidades autónomas (en adelante, CGAA) y, sobre todo, a las cámaras legislativas autonómicas, un menú dispositivo, lo que quiebra la doctrina emanada del Tribunal Constitucional ya que "no es posible concebir unas bases que carezcan de contenido alguno, es decir, que no regulen contenido mínimo común alguno, y se limiten a permitir barra libre a las comunidades autónomas en la regulación completa y sin límite alguno, dado que no existe ese mínimo que debería garantizar el Estado" 2 .

En la misma línea, MARTÍNEZ CORRAL Y VISIEDO MAZÓN señalan que el EBEP ha instaurado un sistema de puertas abiertas en el que es suficiente un delgadísimo tronco común conformado por los preceptos del EBEP como contenido indisponible, acordando este Estatuto la habilitación "[...] a los Parlamentos Autonómicos para prescindir incluso de ese tronco común en la regulación de los funcionarios al servicio del propio Parlamento" ${ }^{3}$.

En definitiva, a pesar de que el EBEP invoca en su Disposición Final Primera tres títulos competenciales, arts. 149.1.18 ${ }^{\mathrm{a}} \mathrm{CE}$, bases del régimen estatutario de los funcionarios, $149.1 .7^{\mathrm{a}} \mathrm{CE}$, legislación laboral y 149.1.13 ${ }^{\mathrm{a}} \mathrm{CE}$, bases y coordinación de la planificación general de la actividad económica, sin embargo, asume la heterogeneidad y renuncia a ordenarla mínimamente ${ }^{4}$

2 FONDEVILA ANTOLÍN, Jorge, La selección y pérdida de la condición de empleado público, Derecho y Administración, Atelier, Barcelona, 2008, p. 35.

3 MARTÍNEZ CORRAL, J. A. y VISIEdO MAZÓN, F. J., "El Estatuto Básico del Empleado Público y su posible aplicación a los Parlamentos autonómicos", en Asamblea: revista parlamentaria de la Asamblea de Madrid, núm. 19 (2008), p. 107.

4 En tal sentido, la Exposición de Motivos del EBEP establece que "el régimen de la función pública no puede configurarse hoy sobre la base de un sistema homogéneo que tenga como modelo único de referencia a la Administración del Estado. Por el contrario, cada Administración debe poder configurar su propia política de personal, sin merma de los necesarios elementos de cohesión y de los instrumentos de coordinación consiguientes. Por tanto, la densidad de la legislación básica en materia de función pública debe reducirse hoy en día, en comparación con épocas pasadas, teniendo en cuenta en todo caso las determinaciones de los Estatutos de Autonomía y la doctrina establecida por el Tribunal Constitucional.

En la misma línea, la Exposición de Motivos establece que "La organización burocrática tradicional, creada esencialmente para el ejercicio de potestades públicas en aplicación de las leyes y reglamentos, se ha fragmentado en una pluralidad de entidades y organismos de muy diverso tipo, dedicadas unas a la prestación de servicios directos a la ciudadanía y otras al ejercicio de renovadas funciones de regulación y control. Esta diversidad de organizaciones ha contribuido igualmente a la heterogeneidad actual de los regímenes de empleo público. La correcta ordenación de este último requiere soluciones en parte diferentes en unos y otros sectores y, por eso, la legislación general básica no puede constituir un obstáculo ni un factor de rigidez. 
Como señala MARTÍNEZ CORRAL Y VISIEDO MAZÓN, “[...] el EBEP no ha definido un modelo, sino que ha establecido un sistema de puertas abiertas, habilitando a las Comunidades Autónomas para regular mediante ley regímenes diferentes de función pública con un delgadísimo tronco común $[\ldots]$... 5 .

En dicha línea, pensamos, que ese delgadísimo tronco común es el que invita a las asambleas parlamentarias a que manifiesten su voluntad para su aplicación del EBEP, pues les permite grandes zonas de disponibilidad ${ }^{6}$.

\section{DESDE LOS INFORMES DE ESTUDIOS PREPARATORIOS PARA EL PRIMER EBEP HASTA LA ACTUALIDAD}

En materia de función pública, la última reforma general anterior al primer EBEP, es la que introdujo la Ley 30/1984, de 2 de agosto, de Medidas para la Reforma de la Función Pública, si bien, era eso, unas medidas para la reforma, pero no constituía per se un estatuto general y básico, a pesar de que la Constitución así lo preveía ${ }^{7}$.

Por Orden APU/3018/2004, de 16 de septiembre, se constituyő la Comisión para el estudio y preparación del EBEP, con la finalidad de "llevar a cabo los análisisy estudios previos así como la elaboración de un documento que sirva de base para la posterior elaboración del anteproyecto" de dicho Estatuto.

La citada Orden considera que el Estatuto debe ser un instrumento legislativo necesario para contar con unas Administraciones públicas plenamente adaptadas a las complejas exigencias sociales de nuestro tiempo.

No podemos entender el EBEP, sin tener en cuenta el proceso de descentralización habido a raíz de la entrada en vigor de nuestra Constitución, que ha transformado de manera radical la Administración General del Estado, y provocando el nacimiento de unas Administraciones autonómicas que integran ya la mayor parte del empleo público, (sin olvidar la Administración Local, que en apenas veinticinco años ha multiplicado por tres sus recursos humanos).

5 MARTÍNEZ CORRAL, J. A. y VISIEDO MAZÓN, F. J., "El régimen del personal al servicio de los parlamentos autonómicos, heterogeneidad o fragmentación: la conveniencia de promover una Conferencia de Cooperación de Administraciones Parlamentarias", en Corts: anuario de Derecho Parlamentario, núm. 22 (2009), p. 160.

6 Aun así, el EBEP permite, como veremos en este epígrafe, a través del art. 4 a) que dichas cámaras legislativas no se apliquen los preceptos que contienen dicho EBEP.

7 En tal sentido, la Orden APU/3018/2004, de 16 de septiembre, considera que el Estatuto, como texto único no se ha aprobado aún, pese a haber transcurridos más de veinticinco años desde la promulgación de la Constitución. 
Como recogió el informe de la Comisión de expertos ${ }^{8}$, en todos estos niveles territoriales de la Administración aparecieron nuevos tipos de entes públicos y se diversificaron sus estructuras, al tiempo que cambiaban parcialmente las funciones asumidas como propias. A todos estos cambios, orgánicos y funcionales, hay que sumar los cambios en la organización del trabajo provocados por las nuevas tecnologías de la información y las comunicaciones en el ámbito administrativo. Ello tiene su incidencia en la composición del empleo público, tanto a nivel cuantitativo como cualitativo, en los perfiles profesionales de sus integrantes, en las necesidades y las posibilidades de promoción y formación y en el régimen de retribuciones. Consecuentemente, estos cambios no son ajenos a los parlamentos autonómicos pues estos son "administraciones" nuevas que, en parte, heredan funcionamientos de la tradicional Administración pública, pero, por otra parte, deben adaptar e innovar en otras áreas, puesto que sus funciones son diferentes a la citada Administración.

Por tanto, es fácilmente constatable la particularidad del personal al servicio de las asambleas parlamentarias de las CAAA en la prestación de los servicios que realiza y, por tanto, debemos entender como lógico, la diversa regulación del mismo en aspectos diferentes.

Tales cambios y problemas respecto a la aplicación de un mismo conjunto de normas jurídicas a todo un conjunto de funcionarios diversos que prestan sus servicios en Administraciones totalmente diferentes exigieron una reforma de la legislación general sobre el empleo público.

En tal sentido, la Comisión constitucional para el estudio y elaboración del EBEP, adoptó como punto de partida en sus trabajos, lo que ya se destacara en el Informe de 25 de abril de 2005, relativo al EBEP, esto es, la constatación de heterogeneidad y falta de uniformidad en lo que se refiere al empleo público debido a la diversidad de regímenes diferentes existentes. Por ello, lo asume e intenta el establecimiento de unas normas mínimas y a la vez unos criterios de flexibilización. En tal sentido, la Exposición de Motivos del EBEP (Ley 7/2007, de 12 de abril, Estatuto Básico del Empleado Público) establece que "el régimen de la función pública no puede configurarse hoy sobre la base de un sistema homogéneo que tenga como modelo único de referencia a la Administración del Estado. Por el contrario, cada Administración debe poder configurar su propia política de personal, sin merma de los necesarios elementos de cohesión y de los instrumentos de coordinación consiguientes."

Probablemente, la intención del legislador fuera la de establecer unas pautas mínimas, respetadas por todos, al objeto de fijar el régimen estatutario de los funcionarios que prevé el art. 149.1.18 ${ }^{\mathrm{a}} \mathrm{CE}$ como competencia exclusiva estatal en materia

8 SÁNCHEZ MORÓn, M. [et al.], Estatuto Básico del Empleado Público: Informe de la Comisión, abril 2005, Instituto Nacional de Administración Pública, Madrid, 2009. 
de fijación de las bases del régimen estatutario de los funcionarios públicos ${ }^{9}$, si bien, debemos hacer hincapié que el citado precepto constitucional se refiere a "las Administraciones públicas".

\section{EL ÁMBITO SUBJETIVO DEL EBEP}

La Comisión para el estudio y preparación del EBEP detalló, en su informe, el ámbito subjetivo en el que debería aplicarse el EBEP, entendiendo que debería englobar "a todos los empleados de todas las Administraciones, organismos y entes que componen el sector público", de una manera amplia, salvo las excepciones que igualmente contempla.

Insiste dicho informe en que el citado ámbito de aplicación debe definirse con cuidado, al objeto de que "no existan grupos de empleados que merezcan la condición de públicos exentos de los principios y reglas comunes que deben regirlo" (a diferencia del pasado), en virtud de "artificios jurídicos o formales".

En consecuencia, deben contemplarse dos cuestiones:

- a los empleados de qué entidades debe aplicarse el Estatuto y,

- si puede o debe haber algún grupo o colectivo de empleados públicos a los que dicho Estatuto no se aplique.

Dedicando el siguiente subepígrafe a la segunda de las cuestiones expuesta, estudiamos la primera cuestión seguidamente, si bien, previamente, debemos hacer una breve reflexión respecto a que hay que entender por sector público.

En consecuencia, habrá que delimitar que se entiende por "sector público" para averiguar si las asambleas legislativas de las CGAA estarían comprendidas en el mismo, a los efectos de la inclusión en el campo subjetivo del EBEP, según las recomendaciones de la Comisión de expertos.

A los efectos indicados, el artículo 19 de la Ley 48/2015, de 29 de octubre, de Presupuestos Generales del Estado para el año 2016, bajo el título "Bases y coordinación de la planificación general de la actividad económica en materia de gastos de personal al servicio del sector público" y cuya estructura se inserta dentro del capítulo I "Del incremento de los gas-

9 "Art. 149.1. El Estado tiene competencia exclusiva sobre las siguientes materias (...) $18^{a}$ Las bases del régimen jurídico de las Administraciones públicas y del régimen estatutario de sus funcionarios que, en todo caso, garantizarán a los administrados un tratamiento común ante ellas (...)". 
tos del personal al servicio del sector público" del Título III "De los gastos de personal", dispone que, a efectos de lo establecido en el citado artículo, constituyen el sector público:

a) La Administración General del Estado, sus Organismos autónomos y Agencias estatales y las Universidades de su competencia.

b) Las Administraciones de las Comunidades Autónomas, los Organismos de ellas dependientes y las Universidades de su competencia.

c) Las Corporaciones locales y Organismos de ellas dependientes.

d) Las Entidades Gestoras y Servicios Comunes de la Seguridad Social.

e) Los Órganos constitucionales del Estado, sin perjuicio de lo establecido en el artículo 72.1 de la Constitución.

f) Las sociedades mercantiles públicas, entendiendo por tales aquéllas en las que la participación, directa o indirecta, en su capital social de las Administraciones y entidades enumeradas en este artículo sea superior al 50 por ciento.

g) Las entidades públicas empresariales y el resto de los organismos públicos y entes del sector público estatal, autonómico y local.

h) Las fundaciones del sector público y los consorcios participados mayoritariamente por las Administraciones y Organismos que integran el sector público.

i) El Banco de España en los términos establecidos en la Ley 13/1994, de 1 de junio, de Autonomía del Banco de España.

j) El Fondo de Reestructuración Ordenada Bancaria (FROB).

Consecuentemente con lo anterior, están comprendidos dentro del ámbito subjetivo de aplicación del EBEP, según las recomendaciones de la Comisión, entre otras, las Administraciones de las CGAA, pero no hace mención del resto de los órganos estatutarios como son sus asambleas legislativas.

Por otra parte, estas cámaras parlamentarias tampoco están incluidas entre los órganos constitucionales del Estado, tal como recoge la letra e) y que únicamente engloba al Congreso de los Diputados, Senado, Gobierno, Tribunal Constitucional y Consejo General del Poder Judicial.

A mayor concreción de lo expuesto anteriormente, el informe de la Comisión de expertos relaciona las Administraciones y Entidades a las que debe aplicarse, explicitando concretamente que "se apliquen las normas comunes del Estatuto Básico del Empleado Público a las relaciones de personal de todas las Administraciones, organismos y entidades públicas, incluidas las fundaciones del sector público y las 
sociedades mercantiles dependientes de una Administración o Ente Público creadas por ellos para satisfacer necesidades de interés general que no tengan carácter industrial o mercantil y que se financien mayoritariamente con fondos públicos, así como a entidades u organismos públicos dotados de autonomía o independencia funcional, sin perjuicio de las leyes y normas especiales que, en el marco del Estatuto Básico, puedan aprobarse en cada caso".

En línea con lo anterior, el EBEP, aprobado por Ley 7/2007, de 12 de abril, dispone en su art. 2.1 (ámbito de aplicación) que se aplica al personal funcionario y en lo que proceda al personal laboral al servicio de las siguientes Administraciones Públicas:

- La Administración General del Estado.

- Las Administraciones de las comunidades autónomas y de las ciudades de Ceuta y Melilla.

- Las Administraciones de las entidades locales.

- Los organismos públicos, agencias y demás entidades de derecho público con personalidad jurídica propia, vinculadas o dependientes de cualquiera de las Administraciones Públicas.

- Las universidades públicas.

Este ámbito de aplicación permanece invariable en el texto del EBEP aprobado por Real Decreto Legislativo 5/2015, de 30 de octubre.

\section{LA LEGISLACIÓN ESPECÍFICA PROPIA DE LAS GÁMARAS PARLAMENTARIAS DE LAS GGAA: EL ART. 4 DEL EBEP}

\section{Informe de la Comisión para el estudio y preparación del EBEP y los textos normativos que lo aprueban}

A. Informe de la Comisión para el estudio y preparación del EBEP

La segunda de las cuestiones que la Comisión para el estudio y preparación del EBEP estudió, respecto al ámbito subjetivo en el que debería aplicarse el citado Estatuto, era si podía o debía haber algún grupo o colectivo de empleados públicos a los que dicho Estatuto no se debiera aplicar.

Las citadas excepciones las justificaba, en el informe que redactó, unas veces por la especificidad de ciertos grupos, o bien porque su estatuto debía ser aprobado, por imperativo constitucional, por medio de ley orgánica o de otro tipo de norma especial, habida cuenta de que el EBEP debía de tener el carácter de ley ordinaria. 
Son, en definitiva, colectivos que en la actualidad ya gozaban, pacíficamente, de un estatuto especial. Se incluyen en estas excepciones:

a) El personal militar profesional y demás personal militar de las Fuerzas Armadas, (excluido el personal civil que presta servicio en la Administración militar).

b) Los miembros de las Fuerzas y Cuerpos de Seguridad, que tienen su estatuto propio regulado por ley orgánica, en virtud de lo previsto en el artículo $104 \mathrm{CE}$, (caso particular de las policías autonómicas y, especialmente las policías locales, cuyo estatuto peculiar afectan sólo a una parte limitada de su relación de servicio).

c) El personal estatutario del Centro Nacional de Inteligencia (dada la contradicción de algunos de los principios básicos del Estatuto, como la publicidad respecto a la asignación de destinos o tareas, al ser incompatibles con su condición).

d) Los Jueces y Magistrados de carrera y el personal al servicio de la Administración de Justicia (art. 122.1 CE) así como los integrantes del Ministerio Fiscal (art. 124.3 CE), aunque en este último caso su estatuto se regule por ley ordinaria.

e) El personal de las Cortes Generales, a tenor de lo previsto en el art. 72.1 CE.

f) El personal de otros órganos constitucionales, como el Tribunal Constitucional, el Tribunal de Cuentas, el Defensor del Pueblo y el Consejo de Estado, cuyas peculiaridades ya eran reguladas por ley orgánica).

g) Los funcionarios retribuidos por arancel (Notarios y Registradores de la Propiedad), que no se integran en la organización administrativa ni perciben sus retribuciones con cargo a fondos públicos.

En resumen, "la Comisión propone excluir de la aplicación directa del Estatuto Básico del Empleado Público a aquellos grupos de funcionarios o empleados que deben tener un estatuto propio y diferenciado en virtud de previsiones constitucionales - miembros de las Fuerzas Armadas y de las Fuerzas y Cuerpos de Seguridad, Fueces, Magistrados y Fiscales, personal al servicio de la Administración de fusticia y personal de los órganos constitucionales- o a otros para los que, por razón de su extraordinaria singularidad, como es el caso de los funcionarios retribuidos por arancel o los del Centro Nacional de Inteligencia, no sean apropiadas la mayoría de los principios y normas comunes del empleo público, sin perjuicio de la aplicación supletoria de aquel Estatuto Básico en los términos que prevea la legislación propia de dichos colectivos".

B. Ley 7/2007, de 12 de abril, y Real Decreto Legislativo 5/2015, de 30 de octubre, que aprueban el EBEP

El art. 4 del EBEP, aprobado tanto por Ley 7/2007, de 12 de abril, como por Real Decreto Legislativo 5/2015, de 30 de octubre, bajo la rúbrica "Personal con legislación específica propia”, establecen que sus disposiciones sólo se aplicarán di- 
rectamente cuando así lo disponga su legislación específica al personal que relacionamos a continuación, pues dicho precepto normativo no ha sufrido variación con la última norma citada:

a) Personal funcionario de las Cortes Generales y de las asambleas legislativas de las CGAA.

b) Personal funcionario de los demás Órganos Constitucionales del Estado y de los órganos estatutarios de las comunidades autónomas.

c) Jueces, Magistrados, Fiscales y demás personal funcionario al servicio de la Administración de Justicia.

d) Personal militar de las Fuerzas Armadas.

e) Personal de las Fuerzas y Cuerpos de Seguridad.

f) Personal retribuido por arancel.

g) Personal del Centro Nacional de Inteligencia.

h) Personal del Banco de España y del Fondo de Garantía de Depósitos de Entidades de Crédito.

C. Aplicación a las asambleas parlamentarias de las CCAA

Respecto a las asambleas parlamentarias de las CAAA, observamos que el informe de la Comisión obvia por completo las mismas y no las cita en ningún caso en las 277 páginas de las que consta el mismo.

Únicamente, establece en el apartado e) del punto $8^{\circ}$ "Inaplicación a determinados colectivos de empleados públicos" el personal de las Cortes Generales al establecer que "debe tener un estatuto propio, regulado en este caso por una norma adoptada de común acuerdo por las Cámaras que la componen (artículo 72.1 de la Constitución)".

No obstante lo anterior, las normas legales referidas anteriormente (Ley 7/2007, de 12 de abril y Real Decreto Legislativo 5/2015, de 30 de octubre), que aprueban los textos que constituyen el EBEP, incluyen como personal con legislación específica propia al personal funcionario de las asambleas legislativas de las CGAA. Entendemos que es una decisión acertada por la analogía y paralelismo que constituyen estos órganos legislativos respecto a las Cortes Generales y, por otra parte, porque, de modo análogo como la Constitución reserva la regulación a través del estatuto del personal para el personal al servicio de las Cortes Generales, diversos EEAA hacen lo propio respecto al personal que presta sus servicios en sus cámaras parlamentarias. 
Si bien, lo habitual en las asambleas legislativas es la carencia de preceptos estatutarios que den cobertura para que sus respectivos EEPP tengan un rango legal y, por tanto, suficiente que los habilite para dotarse de un marco regulador en la materia.

Hay quienes sostienen que el esquema constitucional contenido en el art. 72.1 CE es extensible a los parlamentos autonómicos con independencia de las previsiones estatutarias, como son las previsiones de los reglamentos parlamentarios, o incluso por simple mímesis.

Debemos recordar, a propósito de la autonomía reglamentaria que, tal como establece la STC 179/1989, de 2 de noviembre, FJ $4^{\circ}$ que:

"La Extensión de la autonomía de las asambleas legislativas de las comunidades autónomas viene determinado por el Estatuto de cada una de estas (ya que no existe, a diferencia de las Cortes Generales, una garantía constitucional al respecto [...]”"

La misma STC, respecto a la autonomía organizativa y funcional, establece en el FJ $6^{\circ}$ que:

"No es en modo alguno exigible, en virtud de los mandatos constitucionales, que las instituciones legislativas de las Comunidades Autónomas deban adecuar su estructura, funcionamiento u organización a las correspondientes de las Cortes Generales, ni que deban aplicarse a las Cámaras legislativas de las Comunidades Autónomas, en forma directa o supletoria, las normas constitucionales que regulen la organización y funcionamiento de las Cortes Generales [...]"

En el mismo sentido, la STC 116/1994, de 18 de abril, FJ 5º, al establecer que

"[...] de los preceptos constitucionales que regulan instituciones del Estado no pueden inferirse, sin más, reglas y principios de aplicación, por vía analógica, a las instituciones autonómicas homólogas"

D. Excepción de otros colectivos del art. 4 del EBEP

La jurisprudencia europea tiene como consecuencia una homogeneización del estatuto de los empleados públicos, es decir, funcionarios, laborales, y estatutarios. El EBEP, en concordancia con ello, y con el informe de la Comisión de Expertos, ostenta una línea directriz que es aproximar los regímenes jurídicos del personal laboral y estatutario, unificando en lo posible las normas que sean comunes para su aplicación ${ }^{10}$.

10 SÁnchez MORÓn, M., Prólogo a Comentarios al Estatuto Básico del Empleado Público, Lex Nova, Valladolid, 2007, p. 30 y ss. 
No obstante lo anterior, el art. 4 a) del EBEP únicamente permite una regulación distinta de sus previsiones al personal funcionario que presta sus servicios en las Cortes Generales y en las asambleas legislativas de las CCAA; es decir, el resto del personal que presta sus servicios en las mismas está sometido a preceptos normativos distintos.

En tal línea, el personal laboral está regulado por la legislación del Estado, cuya competencia exclusiva la ostenta, en virtud del art. 149.1.7 $\mathrm{CE}$, por el EBEP, así como por la legislación que, en materia de ejecución, les corresponde a los órganos competentes de las CGAA.

El personal eventual, o de confianza y asesoramiento, se regulará por las disposiciones de la legislación autonómica (art. 12.2 EBEP), ya que el EBEP establece únicamente previsiones generales en relación al nombramiento y cese, el no reconocimiento de su condición a efectos de méritos para el acceso a la función pública o promoción, la publicidad de su número y retribuciones; todo ello, sin perjuicio de la aplicación del régimen general de los funcionarios de carrera "en lo que sea adecuado a la naturaleza de su condición". No obstante, es menester incidir que absolutamente todos los EEPP contienen preceptos reguladores de este tipo de personal que singularizan las disposiciones de la legislación autonómica.

El personal directivo se regula también en el art. 12 del EBEP. Les corresponden a los órganos de gobierno de las CGAA la determinación de su régimen jurídico, así como "los criterios para determinar su condición". No obstante, son las cámaras legislativas las que de forma autónoma deben regular el personal directivo de sus Administraciones parlamentarias. En tal sentido, son los EEPP los que determinan como se designa el citado personal (direcciones generales, jefaturas de servicios...) y las características de las designaciones y nombramientos, si bien, no hay ningún estatuto de personal que haga mención a esta clase de personal como una tipología diferente al resto de los demás colectivos.

Esta carencia reguladora por los EEPP puede ser debida a que este tipo de personal podrá ser desarrollado tanto por el personal laboral como por el personal funcionario, lo que motiva que puedan ser regulados por el EBEP o no, respectivamente, pues podemos hablar de directivos funcionarios, cuyas condiciones, como la negociación colectiva, estarán fijadas por los EEPP (aunque moduladas por las peculiaridades funciones que estos desarrollan); sensu contrario, de lo que sucede si es personal laboral, en cuyo caso, no están sujetos a estas condiciones de negociación colectiva, e incluso, podrá ser reclutados del exterior de la Administración parlamentaria ${ }^{11}$.

11 Nosotros pensamos que no es recomendable el advenimiento del personal del exterior de estas Administraciones parlamentarias, porque el conocimiento idóneo de estas Administraciones es fundamental para el desempeño eficaz de la función directiva, por lo que el directivo laboral "traído de afuera", some- 


\section{Tramitación normativa del EBEP}

Respecto al inicio de la tramitación legislativa del EBEP, en lo que se refiere a este precepto normativo, hemos de señalar que el art. 3 del primer borrador del anteproyecto de ley del EBEP (actual art. 4), de 25 de noviembre de 2005, que relacionaba el personal excluido del ámbito de aplicación de la ley, no hacía mención alguna al personal de las asambleas legislativas de las CCAA, excluyendo solo el personal de las Cortes Generales, entre otros órganos constitucionales.

Sin embargo, el segundo borrador, de 17 de abril de 2006, así como el proyecto de ley del EBEP, enviado por el Gobierno a las Cortes Generales, para su tramitación y aprobación legislativa ${ }^{12}$, recogían en el art. 4 de los mismos, junto con las Cortes Generales, las asambleas legislativas de las CCAA, fijando en la letra a) del citado artículo como personal con legislación específica propia "Personal funcionario de las Cortes Generales y de las asambleas legislativas de las CCAA".

Centrándonos en la tramitación parlamentaria, una vez tuvo entrada en la Cámara el proyecto de ley, se formularon tres enmiendas a la totalidad de devolución, presentadas por los Grupos parlamentarios Mixto, Esquerra Republicana y Popular en el Congreso, si bien, en síntesis, aunque aludieron a la capacidad y/o competencia legislativa en materia de función pública por parte de las CGAA, ninguna de ellas abordaba, ni citaba, la cuestión de la función pública parlamentaria de las respectivas asambleas legislativas de dichas comunidades. Las citadas enmiendas fueron rechazadas por la Cámara y continuó la tramitación legislativa ${ }^{13}$.

Las enmiendas al articulado presentadas al art. 4 del Proyecto de Ley en su tramitación en la Cámara baja, fueron ocho ${ }^{14}$, de las cuales, únicamente dos afecta-

tido a contrato de alta dirección, no es aconsejable para las Administraciones parlamentaria porque podrían generar disfunciones. En la misma línea se manifiesta AUZMENDI DEL SOLAR, M. "Implantación del modelo EFQM de liderazgo en la administración parlamentaria", en Corts: anuario de Derecho Parlamentario, núm. 22 (2009), p. 23.

12 El citado proyecto de ley tuvo entrada en el Registro de la Cámara el día 12 de julio y fue calificado por la Mesa de la Cámara, en sesión celebrada el día 5 de septiembre de 2006, acordando su envío a la Comisión de Administraciones Públicas para su ulterior tramitación y la apertura del plazo para la presentación de enmiendas a dicho texto hasta el día 26 de septiembre, plazo que fue posponiéndose hasta el día 18 de noviembre, tras varias ampliaciones. (Boletín Oficial de las Cortes Generales, Congreso de los Diputados, Serie A, núm. 94-1, de fecha 8 de septiembre de 2006, VIII Legislatura).

13 La votación, de los 310 votos emitidos, dio el siguiente resultado: a favor, 130; en contra, 177; abstenciones, 3. (Diario de Sesiones del Congreso de los Diputados, núm. 210, de fecha 2 de noviembre de 2006, VIII Legislatura).

14 En el Boletín Oficial de las Cortes Generales, Congreso de los Diputados, Enmiendas: Serie A-94-9, de 24 de noviembre de 2006, e Índice de enmiendas al articulado: Serie A-94-10, de 28 de noviembre de 2006, se publicaron las siguientes:

- Enmienda núm. 335 del G.p. Popular. 
ban el apartado a) de dicho artículo, es decir, a las asambleas parlamentarias de las CGAA.

En tal sentido, las presentadas por los Gg.pp. Izquierda Unida-Iniciativa per Catalunya Verds (GIU-ICV), (enmienda núm. 105) y Esquerra Republicana (GERERG), (enmienda núm. 259), proponían la supresión de dicho apartado. Mientras que el primero de los grupos parlamentarios no justificaba la razón de dicha enmienda, si lo hacía Esquerra Republicana, y en tal sentido, exponía como argumentación "Generalizar el ámbito de aplicación del Estatuto, en concordancia con la exposición de motivos, limitando al máximo, en consecuencia, las excepciones, regímenes específicos y normas sectoriales básicas, con el objeto de dar al Estatuto un carácter de marco común para todos los empleados públicos, independientemente de la administración donde presten servicios" ${ }^{15}$.

Dichas enmiendas no se incorporan al Informe de la Ponencia ${ }^{16}$, ni al Dictamen de la Comisión, aunque si se mantienen por ambos Grupos parlamentarios para su defensa y votación en Pleno ${ }^{17}$. Tampoco en el Pleno fueron incorporadas al texto del Proyecto de Ley, enviándose al Senado sin la inclusión de las mismas ${ }^{18}$.

En la tramitación en el Senado, se continuó con la misma línea, no habiendo cambio alguno en relación con el apartado a) del art. 4 del texto normativo ${ }^{19}$.

- Enmienda núm. 105 del G.p. Izquierda Unida-Iniciativa per Catalunya Verds (GIU-ICV), letra a).

- Enmienda núm. 259 del G.p. Esquerra Republicana (GER-ERG), letra a).

- Enmienda núm. 106 del G.p. Izquierda Unida-Iniciativa per Catalunya Verds (GIU-ICV), letra b).

- Enmienda núm. 260 del G.p. Esquerra Republicana (GER-ERG), letra b).

- Enmienda núm. 107 del G.p. Izquierda Unida-Iniciativa per Catalunya Verds (GIU-ICV), letra c).

- Enmienda núm. 261 del G.p. Esquerra Republicana (GER-ERG), letra c).

- Enmienda núm. 108 del G.p. Izquierda Unida-Iniciativa per Catalunya Verds (GIU-ICV), letra e).

15 Véase el Boletín Oficial de las Cortes Generales, Congreso de los Diputados, Serie A-94-9, de 24 de noviembre de 2006

16 Boletín Oficial de las Cortes Generales, Congreso de los Diputados, A-94-11, de 13 de diciembre de 2006 .

17 Boletín Oficial de las Cortes Generales, Congreso de los Diputados, A-94-13, de 20 de diciembre de 2006.

18 Boletín Oficial de las Cortes Generales, Congreso de los Diputados, A-94-14, de 2 de enero de 2007.

19 En la tramitación del Senado, en relación al apartado a) del art. 4, únicamente se presentó la enmienda núm. 200 del G.p. Entesa Catalana de Progrés (GPECP), publicada en el Boletín Oficial de las Cortes Generales, Senado, Serie II, 85 (d), de 21 de febrero de 2007. La argumentación era idéntica a la expuesta anteriormente por el G.p. Esquerra Republicana (GER-ERG) en el Congreso de los Diputados. Tampoco fue incorporada al texto del Proyecto aprobado por el Senado (Boletín Oficial de las Cortes Generales, Senado, Serie II, 85 (f), de 28 de marzo de 2007), aprobándose definitivamente por el Pleno del Congreso de los Diputados el texto el día 29 de marzo de 2007 (Boletín Oficial de las Cortes Generales, Congreso de los Diputados, Serie A, núm. 94-16, de fecha 9 de abril de 2007). 
En consecuencia, durante toda la tramitación parlamentaria de la Ley, no hubo alteración alguna al texto enviado por el Gobierno respecto a la redacción dada en lo que se refiere a las asambleas legislativas de las CGAA como personal con legislación específica propia.

Respecto al EBEP aprobado por Real Decreto Legislativo 5/2015, de 30 de octubre, el mismo fue aprobado por el Gobierno, en virtud de lo dispuesto por la Ley 20/2014, de 29 de octubre, por la que se delega en el Gobierno la potestad de dictar diversos textos refundidos, en virtud de lo establecido en el artículo 82 y siguientes de la Constitución Española. A dicho Proyecto, en lo concerniente al EBEP, únicamente hubo una enmienda del G.p. Socialista, al artículo único, letra g), de supresión, que no fue aceptada y, por tanto, no modificó el texto de la que sería la citada Ley 20/2014 ${ }^{20}$. En conclusión, el apartado a) del art. 4 del EBEP aprobado por Real Decreto Legislativo 5/2015, de 30 de octubre, era idéntico al de la Ley 7/2007, de 12 de abril.

\section{3. ¿Qué ha de entenderse por legislación específica?}

El EBEP no solo ha asumido la autonomía parlamentaria de las asambleas parlamentarias a través de su art. 4, en lo que se refiere a la regulación del personal funcionario al servicio de sus respectivas Administraciones parlamentarias, sino que ha ido aún más allá de lo que en principio podría esperarse al otorgar gran margen de voluntad a las mismas.

A mayor abundamiento de lo anterior, debemos hacer hincapié que el mencionado art. 4 del EBEP establece que sus disposiciones sólo se aplicarán directamente al personal cuando así lo disponga su legislación específica.

Es evidente, y está fuera de toda duda, que la habilitación corresponde de forma exclusiva a las Cortes Generales y parlamentos autonómicos, pero nos planteamos si es necesario que la misma ostente un determinado rango normativo, o si la legislación específica ha de ser mediante normativa interna de la propia cámara o con un ámbito subjetivo mayor, pues el EBEP no concreta más.

20 La motivación de la enmienda era la siguiente: "La Ley del Estatuto Básico del Empleado Público se aprobó el año 2007 (Ley 7/2007, de 12 de abril). La autorización para regularizar, aclarar y armonizar textos legales que contiene el Proyecto de Ley, al no contemplar de forma concreta las normas que se refunden, supone una autorización en blanco al ejecutivo para elaborar un texto normativo con rango de ley en materia de empleo público, lo que contradice las previsiones del artículo 82 de la Constitución". Boletín Oficial de las Cortes Generales, Congreso de los Diputados, Serie A, núm. 67-2, de fecha 21 de febrero de 2014. 
A. El rango normativo

MARTÍNEZ CORRAL Y VISIEDO MAZÓN²1 señalan que debe ser mediante una norma con rango de ley aprobada por la propia cámara la que habilita a autoexcluirse. Pensamos que exigen tal rango normativo de una interpretación literal del susodicho art. 4 del EBEP al establecer "legislación específica" y no cualquier otra expresión.

Respecto al rango normativo que ha de contener la voluntad de las asambleas legislativas y la afirmación de estos autores ${ }^{22}$, queremos hacer dos observaciones:

La primera supondría que el problema se plantea con aquellas asambleas parlamentarias cuyos EEPP no tengan rango de ley. En dichos casos, la solución sería la expresión de la voluntad de la cámara a través de la aprobación de otras normas como pueden ser las leyes de función pública de la respectiva comunidad autónoma e incluso a través de los estatutos de autonomía de las mismas.

Respecto a las leyes de la función pública de las CGAA, solamente a una de ellas, la de Aragón, le es de aplicación a los funcionarios al servicio de dichas Cortes. De tal modo, el Decreto Legislativo 1/1991, de 19 febrero, por el que se aprueba el Texto Refundido de la Ley de Ordenación de la Función Pública, dispone, en el art. $2^{\circ}$, que el ámbito de aplicación se extiende a todo el personal al servicio de la Administración de la Comunidad Autónoma de Aragón, concretando la Disposición Adicional Primera, en su apartado primero, que los funcionarios de las Cortes de Aragón se consideran equiparados a los funcionarios de la Administración de la Comunidad Autónoma de Aragón, y añadiendo el apartado tercero, como excepción, que "la peculiaridad del trabajo parlamentario podrá justificar singularidades del régimen de prestación de trabajo y de su retribución".

21 MARTÍNEZ CORRAL, J. A. y VISIEDO MAZÓN, F. J. (2008: 98-108); MARTÍNEZ CORRAL, J. A., y VISIEDO MAZÓN, F. J. (2009: 148).

22 Otros autores, como SANZ PÉREZ, se limitan a decir con relación a la legislación específica "Cuando se adopte esta decisión por la Mesa parlamentaria (casi siempre), el principio de legalidad será cubierto por el propio EBEP”. Este autor se está refiriendo a los EEPP, los cuales son aprobados en muchos casos por el órgano rector de la cámara parlamentaria, y a la vez, parece que no les está otorgando el rango legal, al decir que el principio de legalidad que se requiere, para el establecimiento de sanciones e infracciones al personal funcionario al servicio de estas asambleas, se obtendrá de la aplicación del EBEP (y consecuentemente, no por el propio estatuto del personal); Véase, a los efectos citados, SANZ PÉREZ, A. L., "Función parlamentaria y potestad disciplinaria: sanciones y procedimiento", en Corts: anuario de Derecho Parlamentario, núm. 22 (2009), p. 239

En consecuencia, al no reconocer en estos casos el rango legal de estos EEPP y, por otra parte, conceder la facultad a las Mesas de los parlamentos a efectos de la legislación específica a la que se refiere el art. 4 del EBEP, está afirmando que no es exigible el rango legal para la aplicación del EBEP. 
El resto de las leyes de la función pública de las CGAA no incluyen en el ámbito de aplicación al personal de sus cámaras legislativas, bien sea por omisión, como sucede en los casos de las CGAA de Andalucía, Canarias, Castilla y León, Navarra y País Vasco ${ }^{23}$; o bien sea porque se excluya expresamente, como sucede en el resto de los casos: Asturias, Illes Balears, Cantabria, Castilla-La Mancha, Cataluña, Extremadura, Madrid, Murcia, La Rioja y Valencia ${ }^{24}$.

Todo ello, sin perjuicio de la aplicación con carácter supletorio de la ley, como establece el art. 3.4 del Decreto Legislativo 1/2008, de 13 marzo, por el que se aprueba el Texto Refundido de la Ley de Función Pública de Galicia.

Una clasificación parecida a la realizada por nosotros, la efectuó CÓLERA $\mathrm{LEIRADO}^{25}$, en la que matizaba que, pese a que la normativa autonómica en materia de función pública aplicable al personal funcionario de los parlamentos autonómicos es dispersa, podían clasificarse en los grupos que se relacionan a continuación. No obstante, queremos indicar previamente que dicha clasificación se muestra desfasada por las modificaciones legislativas habidas, no teniendo justificación la denominación exacta del grupo relativo a "De aplicación directa y parcial", pues la única que supone una aplicación directa (y no parcial) es la correspondiente a las Cortes de

23 Ley 6/1985, de 28 de noviembre, de la Función Pública de Andalucía, Ley 2/1987, de 30 marzo, de la Función Pública de Canarias, Ley 7/2005, de 24 mayo, de Función Pública de Castilla y León, Decreto Foral Legislativo 251/1993, de 30 agosto, por el que se aprueba el Texto Refundido del Estatuto del Personal de la Administración Foral de Navarra y Ley 6/1989, de 6 julio, de Función Pública del País Vasco.

24 Ley 3/1985, de 26 diciembre, de la Función Pública de Asturias (en el Preámbulo se aclara que se excluye al personal al servicio de la Asamblea al entenderse en sentido estricto "la Administración del Principado"), Ley 3/2007, de 27 marzo, de Función Pública de Illes Balears (se excluye al personal al servicio del parlamento (Preámbulo y art. 3.3.a), Ley 4/1993, de 10 marzo, de la Función Pública de Cantabria (en la Disposición Adicional Quinta se excluye al personal al servicio de la Asamblea, que se regulará por su EP), Ley 4/2011, de 10 marzo, de Empleo Público de Castilla-La Mancha (solo se aplicará cuando así lo disponga su legislación específica (art. 8.2.a), Decreto Legislativo 1/1997, de 31 octubre, por el que se aprueba la refundición en un Texto único de los preceptos de determinados textos legales sobre la función pública de Cataluña (queda excluido el personal del parlamento de Cataluña (art. 2.3.a)), Ley 13/2015, de 8 abril, de Función Pública de Extremadura (solo se aplicará cuando así lo disponga su legislación específica (art. 3.6.a)), Ley 1/1986, de 10 abril, de la Función Pública de Madrid (en el Preámbulo y en el art. 3.3 se excluye al personal al servicio de la Asamblea), Decreto Legislativo 1/2001, de 26 enero, por el que se aprueba el Texto Refundido de Ley de Función Pública de Región de Murcia ("No se integra en la Función Pública regional [...] el personal que presta servicios en la Asamblea Regional” (art.3.2.a)), Ley 10/2010, de 9 julio, de Ordenación y Gestión de la Función Pública Valenciana (solo se aplicará cuando así lo disponga su legislación específica (art. 3.6.a)) y Ley 3/1990, de 29 junio, de Función Pública de la Administración Pública de la Comunidad Autónoma de La Rioja (en el Preámbulo se aclara que se excluye al personal al servicio de la Diputación General de la Rioja (antigua denominación del Parlamento de La Rioja), al entenderse en sentido estricto "la Administración de la Comunidad Autónoma de La Rioja").

25 CÓlERA LEIRADO, J. R., "La función pública de los parlamentos autonómicos y su enjuiciamiento jurisdiccional", en Corts: anuario de Derecho Parlamentario, núm. 17 (2006), p. 111-182. 
Aragón, y no teniendo ninguna validez el último de los grupos indicados, el relativo a "vinculación por equiparación", tal como se explica en nota a pie página:

De exclusión: Son aquellas CGAA, cuyos ámbitos de aplicación de la legislación autonómica, no hacen referencia, o excluyen de forma expresa, al personal al servicio de estas Administraciones parlamentarias ${ }^{26}$.

De aplicación supletoria: Se incluyen aquellas leyes de función pública que declaran de forma expresa la aplicación supletoria al personal de estas cámaras.

De aplicación directa y parcial: Se incluyen las CGAA que tienden a homogeneizar determinadas regulaciones de la Administración de la comunidad autónoma y la Administración de estas cámaras. A tales efectos, regulan aspectos o cuestiones concretas como la movilidad de sus funcionarios.

De vinculación por equiparación: Forman parte de este grupo aquellas CGAA que equiparan en sus leyes de función pública a los funcionarios de sus asambleas parlamentarias con los de la Administración de esas $\mathrm{CCAA}^{27}$.

Pensamos que, probablemente, en aras de una mejor defensa de la autonomía parlamentaria, hubiera sido más acertado cambiar la expresión "legislación específica" por otra similar a "normativa específica", es decir, que no sea exigible el rango de ley para la normativa interna de la asamblea parlamentaria.

No obstante lo anterior, desde otro punto de vista, es más coherente la interpretación de exigencia de un rango de ley si ponemos en concordancia el EBEP como normativa básica con lo que dispone la Constitución en su art. 149.1.18ª CE. A mayor explicitación de ello:

26 Tampoco este grupo permanece invariable a la composición que realizaba el autor citado, pues si en 2006, incluía a nueve Administraciones parlamentarias (Andalucía, Asturias, Canarias, Cantabria, Castilla y León, Cataluña, Madrid, Murcia y La Rioja), hoy podemos incluir a quince, a saber, todas menos Aragón (aplicación directa) y Galicia (aplicación con carácter supletorio).

27 Incluía CÓLERA LEIRADO en este epígrafe la normativa autonómica valenciana pues señalaba el autor que "la función pública expresamente equipara a los funcionarios de las Cortes con los de la Administración de la Comunidad Autónoma". A este respecto, es necesario aclarar que si bien el art. 1 del Decreto-Legislativo, de 24 de octubre de 1995, del Gobierno Valenciano, por el que se aprueba el Texto refundido de la Ley de Función Pública Valenciana, disponía en el apartado a) que sería de aplicación al personal al servicio de la Generalitat Valenciana determinado en el artículo 2. Y el apartado primero del artículo citado determinaba que es personal al servicio de la Generalitat Valenciana, entre otros, el de las Cortes Valencianas; actualmente, dicha Ley es derogada por la Ley 10/2010, de 9 de julio, de Ordenación y Gestión de la Función Pública Valenciana, estableciendo el art. 3, apartado $6^{\circ}$, de la misma, que las disposiciones de esta Ley sólo serán aplicables al personal al servicio de Les Corts cuando así lo determine su legislación específica, y en los términos previstos en ésta. 
- La Disposición final primera del EBEP, bajo la signatura "Habilitación competencial", establece que "las disposiciones de este Estatuto se dictan al amparo del artículo 149.1.18 de la Constitución, constituyendo aquellas bases del régimen estatutario de los funcionarios". Si bien, únicamente tendrán carácter básico los preceptos del EBEP para los funcionarios incluidos de forma expresa en el ámbito de aplicación de dicha Ley. Para todos los demás funcionarios, tienen carácter supletorio ${ }^{28}$. (Excepción hecha del personal laboral, directivo y eventual cuyo art. 4 del EBEP no contempla).

- El art. 149.1.18 $\mathrm{CE}$ dispone que le corresponde al Estado "las bases del régimen jurídico de las Administraciones públicas y del régimen estatutario de sus funcionarios $[\ldots]$ ".

- La Disposición final segunda del EBEP dispone que "las previsiones de esta ley son de aplicación a todas las comunidades autónomas respetando en todo caso las posiciones singulares en materia de sistema institucional y las competencias exclusivas y compartidas en materia de función pública y de autoorganización que les atribuyen los respectivos Estatutos de Autonomía, en el marco de la Constitución".

- Este precepto constitucional no supone en materia de función pública parlamentaria que sea una competencia exclusiva a favor del Estado, por lo que las asambleas legislativas de las CCAA podrán asumir la misma a través de sus EEAA, de conformidad con lo dispuesto en el art. 149.3 in initio y 147.2 d) CE.

- Esos mismos EEAA podrán establecer la competencia de estas asambleas para la elaboración y aprobación de sus respectivos EEPP, constituyendo así una reserva competencial propia y exclusiva de las mismas (epígrafe $8^{\circ}$ citado).

- La fijación de estas previsiones normativas por los EEAA a favor de sus cámaras legislativas (reserva de sus EEPP), de modo análogo a como lo hace la Constitución (art. 72.1 CE) respecto a su EPCG, hacen que dichos EEPP "puedan" ostentar la nota de primariedad, y de este modo disponer del rango de ley (si reúnen otros requisitos que no son objeto de estudio en este artículo). Todo ello de conformidad con la jurisprudencia actual, tanto Constitucional, como del Tribunal Supremo, que exigen la existencia de una conexión o vinculación directa con el Estatuto de autonomía respectivo ${ }^{29}$.

28 En el mismo sentido MARTÍNEZ CORRAL, J. A., y VISIEDO MAZÓN, F. J. (2009: 149).

29 ATS de 10 de octubre de 1989, (RJ 1989\6857), en relación con el extinto Estatuto de Régimen y Gobierno Interior, de 10 de enero de 1986 (derogado por el EPNAV, aprobado por Acuerdo, de 20 de marzo 1991, de la Comisión de Reglamento del Parlamento de Navarra) y STC 183/2012, de 17 de 
Sintetizando ambas líneas, la constitucional y la legal, los EEPP que dispongan de rango legal podrán disponer libremente que se aplique directamente el EBEP, o no, y no resultarle de aplicación el art. 149.1.18 ${ }^{\mathrm{a}}$ $\mathrm{CE}$, pues las competencias les corresponden a las asambleas parlamentarias que han expresado esa voluntad.

A sensu contrario, los EEPP que no tienen rango de ley, en virtud de lo establecido en el art. 4 del EBEP, no podrán disponer la aplicación directa del citado Estatuto Básico.

- Respecto a la segunda de las observaciones a la que aludíamos anteriormente, estos autores afirman que "[la disposición] habilita exclusivamente a las Cortes Generales y a las Asambleas Legislativas a autoexcluirse, mediante una norma con rango de ley" 30 .

- No compartimos la afirmación anterior, pues el art. 4 del EBEP establece que sólo "se aplicarán directamente cuando asi lo disponga su legislación específica"; A sensu contrario, si la legislación específica no dispone nada, no se aplicará directamente el EBEP, mientras que para MARTÍNEZ CORRAL y VISIEDO MAZÓN es necesario la citada legislación específica para autoexcluirse. En otras palabras, entendemos que, "en principio", las cámaras legislativas están excluidas de la aplicación del EBEP; únicamente les será preciso una norma con rango de ley para incluirse en la misma, pues si no manifiestan voluntad alguna, y a través de una ley, se mantendrán en la exclusión del ámbito de aplicación.

- Consecuentemente, tal como hemos indicado anteriormente, de una interpretación literal del art. $4^{\circ}$ del EBEP, puede darse el caso de que alguna asamblea parlamentaria tenga la voluntad de disponer de una aplicación directa del EBEP, pero que por no ostentar su estatuto del personal del referido rango legal no pueda aplicarse.

B. Tipo normativo: EEPP, leyes de función pública de las CGAA o EEAA

En otro orden de cosas, y con un enfoque diferente al examinado en los párrafos anteriores, podemos preguntarnos en relación con lo que debemos entender por legislación específica si ¿únicamente es la que establece la cámara parlamentaria autonómica cuando realiza su facultad autonormativa en relación con su propio per-

octubre, consecuencia de la cuestión de inconstitucionalidad relativa a las Normas de Gobierno Interior del Parlamento de Canarias, en las que en ambos pronunciamientos se pone en valor la primariedad de las citadas normas respecto a la LORAFNA y el Estatuto de Autonomía de Canarias, respectivamente; ambos, (ATS y STC citados) en la misma línea que la STC 139/1988, de 8 de julio.

30 Véase MARTÍNEZ CORRAL, J. A., y VISIEdO MAZÓN, F. J. (2008: 148). 
sonal, a través de su estatuto del personal?, ¿la que establece la asamblea legislativa a través de las leyes de función pública de su comunidad autónoma? o ¿la expresada a través del estatuto de autonomía de la comunidad autónoma en cuestión?.

De tal modo, el Estatuto de autonomía de Extremadura establece que el Estatuto del personal de su asamblea será en el marco de la ley de su función pública y ésta se somete al EBEP ${ }^{31}$, ¿quiere decir ello que está supeditando el estatuto del personal al EBEP? ¿O debemos entender por legislación específica solo lo expresamente aprobado por la propia cámara parlamentaria?

En cualquier caso, es la propia Asamblea de Extremadura, con la aprobación de su nuevo Estatuto del Personal, aprobado por el Pleno, en sesión celebrada el día 26 de junio de $2014^{32}$, la que aclara tal situación, al contener en la Exposición de Motivos lo siguiente:

"Para justificar la necesidad de este estatuto cabe señalar que el texto actualmente en vigor solo fue publicado en el Boletín Oficial de la Asamblea de Extremadura con dudas, por tanto, sobre su vigencia. Se trata, además, de una norma que data del año 1996, tiempo en el que se ha producido una importante evolución normativa tanto en la Administración del Estado como en las normas autonómicas extremeñas, y en el que destaca la aprobación del Estatuto Básico del Empleado Público, que al no tratarse de una norma de inmediata aplicación en los parlamentos autonómicos no había podido transponerse a la Asamblea de Extremadura".

Pensamos que el EBEP al decir "legislación específica" se está refiriendo a la legislación correspondiente a las cámaras parlamentarias y, por tanto, a lo que establezcan sus EEPP respectivos. No obstante lo anterior, no hay impedimento jurídico alguno para que la voluntad de las Cámaras se expresen a través de otros instrumentos jurídicos, como pueden ser a través de sus propios EEAA, o a través de otras leyes de función pública, pues sin duda, todos estos instrumentos tienen un único sujeto, que es su parlamento autonómico, si bien, pensamos, que lo idóneo es que sea la propia cámara legislativa autonómica la que exprese su voluntad por medio de normas internas (legislación específica como los EEPP), en virtud de la autonomía autonormativa de la que gozan, y sin intervención alguna del Gobierno autonómico.

Ejemplo de ello lo constituía el personal al servicio de la Generalitat Valenciana. Al contrario de lo que ocurre con el EBEP, caracterizado por el escrupuloso

31 El art. 16.1, bajo la rúbrica "Carácter y atribuciones", de la Ley Orgánica 1/2011, de 28 de enero, de reforma del Estatuto de Autonomía de la Comunidad Autónoma de Extremadura, establece en el apartado $2^{\circ}$, que corresponde a la Asamblea de Extremadura: "[...] e) Aprobar el estatuto del personal de la Asamblea en el marco del régimen general de los empleados públicos de la Comunidad Autónoma”.

32 Boletín Oficial de la Asamblea de Extremadura (BOAE) n ${ }^{\circ} 576$, de 30 de junio de 2014. 
respeto a la autonomía parlamentaria, la legislación en materia de función pública valenciana si realizaba previsiones sobre el personal de su cámara parlamentaria, las Cortes autonómicas. Se pretendía por el legislador valenciano una uniformidad y generalización del régimen jurídico de aplicación, pero a la vez, llama la atención que, desde una ley sectorial, como es la regulación de la función pública, se afirme la autonomía administrativa de las Cortes, aunque, de hecho, sin aportar nada, a la autonomía parlamentaria de dicha Cámara.

En tal sentido, el art. 1 del Decreto-Legislativo, de 24 de octubre de 1995, del Gobierno Valenciano, por el que se aprueba el Texto refundido de la Ley de Función Pública Valenciana, disponía en el apartado a) que sería de aplicación al personal al servicio de la Generalitat Valenciana determinado en el artículo 2. Y el apartado primero del artículo citado determinaba que es personal al servicio de la Generalitat Valenciana, entre otros, el de las Cortes Valencianas.

A pesar de que el segundo párrafo de dicho apartado establecía que "Las Cortes Valencianas, en virtud de su autonomía organizativa, administrativa y financiera, desarrollarán la presente Ley, mediante el establecimiento del régimen del personal dependiente de las mismas, atendidas las características especiales de la actividad parlamentaria”, ello no es óbice para su crítica, pues aunque incidía en la autonomía administrativa de las Cortes Valencianas, la limitaba, pues de la lectura del precepto, se desprende que el punto de partida es lo dispuesto en la Ley citada de Función Pública Valenciana, dejando únicamente a dicha Cámara parlamentaria la labor de desarrollo y adecuación a sus necesidades, pues dicha regulación parlamentaria no podría ser independiente a lo establecido en dicha Ley. De hecho, se limitaba la autonomía parlamentaria, pues no es entendida la Ley para cubrir lagunas que el Estatuto del personal de las Cortes Valencianas no preveía, sino que dicho Estatuto únicamente debía regular singularidades de la actividad parlamentaria ${ }^{33}$.

DÍEZ SÁNCHEZ, respecto a la autonomía administrativa de las Cortes, directamente relacionada con la materia de personal que es el objeto de la Ley, estima que no es "[...] apropiado llevarla a cabo en una Ley que entre sus objetivos no está identificar las prerrogativas consustanciales de que dispone el Parlamento en materia de personal' ${ }^{\text {34 }}$.

Posteriormente, dicha Ley es derogada por la Ley 10/2010, de 9 de julio, de Ordenación y Gestión de la Función Pública Valenciana. Actualmente, el art. 3, apar-

33 A los meros efectos ilustrativos, es evidente que menoscaba la autonomía parlamentaria el hecho de que la Consejería de Administración Pública pudiera imponer un representante de la misma, aunque fuera a los efectos de función de asesoramiento, tal como preveía el art. 13.3. b) del mencionado Decreto-Legislativo.

34 DÍEZ SÁNCHEZ, J. J, "Autonomía administrativa parlamentaria: las cuestiones relativas al personal parlamentario y su control judicial", en Corts: anuario de Derecho Parlamentario, núm. 16 (2005), p. 58. 
tado $6^{\circ}$, de la misma, establece que las disposiciones de esta Ley sólo serán aplicables al personal al servicio de Les Corts cuando así lo determine su legislación específica, y en los términos previstos en ésta.

Decisión esta última que creemos más apropiada con lo que ha de entenderse por legislación específica que establece el EBEP y más respetuosa con la autonomía parlamentaria de las asambleas legislativas de las CGAA, por lo que rectifica lo que establecía el Decreto-Legislativo, de 24 de octubre de 1995, del Gobierno Valenciano, en lo que se refiere al personal al servicio de las Cortes Valencianas, ya que son cuestiones que únicamente corresponde realizar a la propia Cámara Valenciana, a través de su normativa interna, como constituye su Estatuto del Personal.

\section{CONSEGUENGIAS JURÍDICAS DE LA LEGISLACIÓN ESPECÍFICA}

Las cámaras parlamentarias deberán optar, en su regulación normativa, a través de sus respectivos EEPP, si desean que se aplique directamente los preceptos del EBEP al personal funcionario que presta sus servicios en las mismas.

El art. 4.a) del EBEP establece que es aplicable cuando así lo disponga su legislación específica, por lo que la decisión podrá tener consecuencias diferentes:

- Si el EBEP se aplica directamente al personal funcionario que presta sus servicios en la cámara, porque así lo establece el estatuto del personal de la misma, implica que el EBEP, que ha necesitado del estatuto del personal, lo condicionará y limitará a partir de entonces, puesto que el EBEP es norma básica dictada por el Estado. Si bien, como hemos manifestado anteriormente, esas bases no les son de aplicación, una vez expresada la voluntad de la asamblea legislativa, las mismas si les serán de aplicación en tal sentido. Consecuentemente, parece lógico pensar que las referencias que el EBEP hace a su desarrollo por la legislación autonómica, se deben entender referidas también al estatuto del personal.

- Pero esta posibilidad que ofrece el EBEP no es igual para todas las asambleas legislativas de las CGAA puesto que no todas ellas han aprobado sus respectivos EEPP bajo las mismas condiciones y, por tanto, no todos gozan del mismo rango y fuerza legal. En consecuencia, la mayoría de las cámaras legislativas no podrán disponer la aplicación del EBEP, a través de sus respectivos EEPP, de conformidad con lo que dispone el art. 4 del Estatuto Básico.

- Ello está en consonancia con lo que declara el Tribunal Constitucional en reiterada jurisprudencia, en relación con el art. 72.1 CE, para el 
personal de las Cortes Generales en cuánto que no es extensible a los parlamentos autonómicos.

- E incluso podemos aludir al propio informe de la Comisión de Expertos que no excluía la aplicación directa a estas cámaras autonómicas, mientras que sí lo hacía respecto al personal funcionario de las Cortes Generales.

- Respecto a la aplicación a las asambleas legislativas de las CCAA de las previsiones contenidas en el EBEP, NAVARRO MÉNDEZ ${ }^{35}$ señala que las mismas pueden pasar a su propio marco regulador a través de una norma con rango de ley, y ser directamente aplicables al personal de la cámara respectiva, a través de dos medios:

- Técnica de remisión: Si se reenvía al EBEP la regulación de determinadas cuestiones.

- Técnica de incorporación: Si se traslada al cuerpo normativo propio todo o parte de la regulación contenida en el EBEP.

Nosotros pensamos, no obstante, que el rango legal será únicamente necesario para disponer la aplicación íntegra del EBEP al personal funcionario de las asambleas legislativas y este se constituirá como normativa básica del mismo, condicionando y limitando al estatuto del personal desde ese momento.

En los casos en los que el propio estatuto del personal disponga la aplicación de cualquier norma ajena al mismo (incluido el EBEP), ya sea por remisión, o por incorporación, no será necesario que el referido estatuto del personal tenga rango legal pues los preceptos del EBEP, como de cualquier otra norma, se aplicarán al personal funcionario de la cámara legislativa, pero no en virtud de su rango, sino como meras disposiciones normativas que el estatuto del personal a la que se remite o incorpora, pero de forma sesgada y aislada.

No constituye, por tanto, la forma de aplicación a la que se refiere el art. 4.a) del EBEP.

- Si los EEPP, simplemente, no disponen la referida aplicación, mediante el instrumento legal, el EBEP no puede aplicarse directamente al personal de las asambleas legislativas.

35 NAVARRO MÉNDEZ, J. I., "Reflexiones sobre la contribución del Estatuto Básico del Empleado Público a la modernización de la Función Pública Parlamentaria Autonómica”, en Revista de Derecho de Extremadura, núm. 3 (2008), p. 214. 
- No obstante, al amparo de lo dispuesto en el art. 2.5 del EBEP, el mismo "tiene carácter supletorio para todo el personal de las Administraciones Públicas no incluido en su ámbito de aplicación” y, por tanto, podría aplicarse a los EEPP que han sido elaborados en ausencia de un título competencial a favor de sus respectivas cámaras legislativas. Recordemos la STC 61/1997, de 20 de marzo, al amparo de la cual, el Estado no puede dictar normas con carácter supletorio respecto al derecho autonómico de las CCAA, salvo que tenga un título específico que le habilite tal competencia. Es decir, en aquellos casos que los EEPP hayan sido aprobados en virtud de una previsión estatutaria, al constituir la misma una competencia específica a favor de las asambleas legislativas de las CGAA, implicaría que el Estado, al carecer de título específico en la materia, no pueda constituirse como Derecho supletorio de dichas asambleas, salvo que sean las propias asambleas, las que a través de su propia normativa se remitan a dicha Ley.

- Pero, además de la supletoriedad impuesta, también podrá constituir una supletoriedad pedida porque sean los propios EEPP los que establezcan el EBEP como Derecho con carácter supletorio.

- En estos casos de supletoriedad del EBEP, ante la ausencia de normativa básica del Estado, la normativa sobre función pública autonómica se erige en el marco normativo de referencia. Debemos recordar que el EBEP derogó la normativa básica en materia de función pública anterior al mismo.

Si los EEPP optan por la no aplicación del EBEP a su personal funcionario, se establece un marco jurídico diferente, que se explicita en los párrafos siguientes.

\section{LÍMITES JURÍDICOS DE LAS ASAMBLEAS PARLAMENTARIAS DERIVADOS DE LA NO APLICACIÓN DEL EBEP}

Si las cámaras parlamentarias autonómicas pueden decidir con relación a la aplicación del EBEP respecto a los funcionarios que prestan sus servicios en las mismas, de conformidad con el art. 4 del EBEP, surge la cuestión de si existe algún límite jurídico a estas cámaras respecto a la cuestión planteada.

En síntesis, los EEPP, así como cualquier otra norma aprobada, tanto por la asamblea parlamentaria, como por el Consejo de Gobierno de la comunidad autónoma en cuestión, deberán serlos en el marco de lo establecido por el texto constitucional y estatutario de la comunidad autónoma. Por ello, con independencia de 
la aplicación o no del art. 149.1.18 ${ }^{\mathrm{a}}$ CE a esos EEPP, existe una estructura jurídica constitucional que le es de aplicación a la función pública, y sin distinción alguna, en este aspecto, de si se trata de la Administración pública o de la Administración parlamentaria.

De hecho, el estudio sistemático de los arts. 23.2, 25.1 y 149.1.1 ${ }^{\text {a }} \mathrm{CE}$ (sin perjuicio de otros preceptos como el art 103.3 CE, cuya aplicación es discutible a las asambleas parlamentarias a la vista del tenor literal y de su encuadramiento y del cual no existe acuerdo en la doctrina jurídica) en concordancia con algunos EEAA, en su caso, (en aquellas CCAA en las cuales habilitan a sus asambleas legislativas para la aprobación de sus respectivos EEPP) y con los reglamentos parlamentarios (que autorizan también, en ocasiones, a la cámara parlamentaria para la aprobación de los citados EEPP) y, para finalizar, de conformidad con la legislación en materia de función pública aprobada por las CCAA en los casos que contengan algún precepto relativo a la aplicación (o no) del EBEP a sus respectivas asambleas parlamentarias, configuran un escenario en el cual ha de desenvolverse la actuación de los parlamentos autonómicos en relación al personal que presta sus servicios en los mismos.

Esa actuación, además, deberá ser conforme con la jurisprudencia del Tribunal Constitucional en la materia, así como con la aplicación transversal de otras normas estatales (cfr. tipificación de los delitos cometidos por los funcionarios públicos contemplados en el Código Penal).

Por último, parece constituir derecho dispositivo por parte de las asambleas parlamentarias la aplicación supletoria del EBEP a su personal funcionario, a pesar de lo dispuesto en el art. 4 del EBEP, pues el art. 2.5 del referido Estatuto establece que "tiene carácter supletorio para todo el personal de las Administraciones Públicas no incluido en su ámbito de aplicación".

En el mismo sentido, existe algún autor, como SORIANO HERNÁNDEZ, que señala que "[...] solo cuando la regulación específica del Parlamento establezca la aplicación directa o la supletoriedad del Estatuto Básico, este podrá configurarse como tal" ${ }^{36}$.

36 SORIANO HERNÁNDEZ, E., "Aplicación del Estatuto Básico del Empleado Público al personal al servicio de los parlamentos: en especial al personal de Corts Valencianes", en Corts: anuario de Derecho Parlamentario, núm. 22 (2009), p. 286. 


\section{BIBLIOGRAFÍA}

AUZMENDI DEL SOLAR, M. "Implantación del modelo EFQM de liderazgo en la administración parlamentaria", en Corts: anuario de Derecho Parlamentario, núm. 22 (2009), p. 17-31.

CÓLERA LEIRADO, J. R., "La función pública de los parlamentos autonómicos y su enjuiciamiento jurisdiccional", en Corts: anuario de Derecho Parlamentario, núm. 17 (2006), p. 111-182.

DÍEZ SÁNCHEZ, J. J, “Autonomía administrativa parlamentaria: las cuestiones relativas al personal parlamentario y su control judicial", en Corts: anuario de Derecho Parlamentario, núm. 16 (2005), p. 23-76.

FONDEVILA ANTOLÍN, Jorge, La selección y pérdida de la condición de empleado público, Derecho y Administración, Atelier, Barcelona, 2008.

MARTÍNEZ CORRAL, J. A. y VISIEDO MAZÓN, F. J., "El Estatuto Básico del Empleado Público y su posible aplicación a los Parlamentos autonómicos", en Asamblea: revista parlamentaria de la Asamblea de Madrid, núm. 19 (2008), p. 93-132.

- "El régimen del personal al servicio de los parlamentos autonómicos, heterogeneidad o fragmentación: la conveniencia de promover una Conferencia de Cooperación de Administraciones Parlamentarias", en Corts: anuario de Derecho Parlamentario, núm. 22 (2009), p. 145-178.

NAVARRO MÉNDEZ, J. I., "Reflexiones sobre la contribución del Estatuto Básico del Empleado Público a la modernización de la Función Pública Parlamentaria Autonómica", en Revista de Derecho de Extremadura, núm. 3 (2008), p. 206-232.

SÁNCHEZ MORÓN, M. [et al.], Estatuto Básico del Empleado Público: Informe de la Comisión, abril 2005, Instituto Nacional de Administración Pública, Madrid, 2009.

SÁNCHEZ MORÓN, M., Prólogo a Comentarios al Estatuto Básico del Empleado Público, Lex Nova, Valladolid, 2007.

SANZ PÉREZ, A. L., "Función parlamentaria y potestad disciplinaria: sanciones y procedimiento", en Corts: anuario de Derecho Parlamentario, núm. 22 (2009), p. 229-250.

SORIANO HERNÁNDEZ, E., "Aplicación del Estatuto Básico del Empleado Público al personal al servicio de los parlamentos: en especial al personal de Corts Valencianes", en Corts: anuario de Derecho Parlamentario, núm. 22 (2009), p. 273-292. 